\title{
Cervical Atypical Polypoid Adenomyoma
}

National Cancer Institute

\section{Source}

National Cancer Institute. Cervical Atypical Polypoid Adenomyoma. NCI Thesaurus. Code C40234.

An adenomyoma that arises from the cervix and is characterized by the presence of a glandular component exhibiting architectural complexity. 